\title{
Teaching spontaneous responses to a young child with Down syndrome
}

\section{Kathleen Feeley ${ }^{1}$ and Emily Jones ${ }^{2}$}

Children with Down syndrome experience significant communication impairments, particularly in expressive language. Although receiving little attention in the literature, deficiencies in expressive language are likely to affect spontaneous communicative responses in children with Down syndrome. In this study, using a multiple baseline design across responses, we demonstrated the effectiveness of discrete trial instruction in establishing spontaneous responses in a preschooler with Down syndrome.

Spontaneous responses generalised to a novel setting involving a novel person and novel materials. Implications for the use of behaviourally based interventions to address the social-communicative needs of children with Down syndrome are discussed.

Children with Down syndrome experience significant impairments in communication across a range of skills including articulation, morphology, syntax, and semantics ${ }^{[1-3]}$. While both receptive and expressive language are specifically impaired, the expressive language of children with Down syndrome lags further behind their receptive capabilities ${ }^{[4]}$, affecting interactions with family, peers, and community members ${ }^{[5]}$.

An area of expressive language in children with Down syndrome receiving little attention in the literature is spontaneity, defined by Charlop, Schreibman, and Thibodeau as "a verbal response to a nonverbal discriminative stimulus in the absence of a verbal discriminative stimulus" (REF 6, p.156). For example, a child spontaneously comments, "I see a bird," in response to a bird flying (the discriminative stimulus $\left[\mathrm{S}^{\mathrm{D}}\right]$ ), or says "Thank you" upon receiving a new toy $\left(\mathrm{S}^{\mathrm{D}}\right)$. In contrast, many children with communication impairments verbalise only in response to an adult's vocal directions to do $\mathrm{so}^{[7]}$, such as commenting only when asked "What do you see?" or saying "Thank you" only when told "Say "Thank you." Nonverbal stimuli to which children emit spontaneous utterances do not include explicit adult vocalisations, rather the important features may include nonvocal components (e.g., a bird flying) or the action of another person (e.g., presenting a new toy).

The impaired expressive language affects the communicative competence of young children with Down syndrome, including the spontaneity of language, further limiting their opportunities to interact with others. The child may not have acquired the appropriate verbal response to be emitted within the specific context. Additionally, a variable likely to affect spontaneity is the decreased saliency of nonverbal stimuli. Specifically, nonverbal stimuli may not be salient enough to exert control over a child's communicative behaviour.

Researchers have addressed spontaneity in children with autism (for whom spontaneity is often impaired) using intensive intervention procedures (in which multiple teaching opportunities were presented in close proximity with unrelated reinforcers delivered for correct responding) including teaching spontaneous requests (e.g. REF 6-8), expressions of affection (e.g. REF 9), social niceties (e.g. REF 10), greetings (e.g. REF 11), and comments (e.g. REF 12). Naturalistic teaching strategies (i.e., intervention implemented during naturally occurring routines) have also been utilised to teach spontaneous communication to children with autism ${ }^{[13]}$.

Two studies addressing spontaneous communication in children with Down syndrome also utilised naturalistic teaching strategies. Warren, Yoder, Gazdag, Kim and Jones ${ }^{[14]}$ taught a 20 month old boy with Down syndrome to comment on the presentation of a novel item. Hemmeter,
(1) Department of Special Education and Literacy, C.W. Post Campus of Long Island University, 720 Northern Boulevard, Brookville, New York 11548, USA

(2) Department of Psychology, C.W. Post Campus of Long Island University, 720 Northern Boulevard, Brookville, New York 11548, USA

Correspondence to Dr. Kathleen Feeley•e-mail: kathleen.feeley@ liu.edu

doi:10.3104/case-studies.2007

(c) 2007 The Authors. Journal Compilation ๑ 2008 Down Syndrome Education International. 
Ault, Collins and Meyer ${ }^{[15]}$ taught spontaneous responses to two children with Down syndrome (7.2 and 5.9 years). One child, who was taught spontaneous requesting (e.g., saying, "More"), showed poor maintenance and generalisation. For the second child, who was taught to comment (e.g., saying, "Big ball"), prompted comments increased during intervention, but there was little spontaneous commenting with no generalisation.

In a previous study, we addressed spontaneity in two preschoolers with autism using an intensive behavioural intervention (i.e., discrete trial instruction) ${ }^{[16]}$. In this study, we examined the same intervention to teach spontaneous responses to a child with Down syndrome.

\section{Method}

\section{Participant}

Max, a 3 year 9 month old boy with Down syndrome, participated in this study. At the time, Max's expressive and receptive language scores fell between one half and one standard deviation below the mean on the Preschool Language Scale Third edition ${ }^{[17]}$. On the Goldman-Fristoe Test of Articulation ${ }^{[18]}$, Max performed at the $1^{\text {st }}$ percentile. On the Learning Accomplishment Profile-Diagnostic Standardized Assessment (LAP-DO) ${ }^{[19]}$ Max performed at the $21^{\text {st }}$ percentile for language, $85^{\text {th }}$ percentile for cognitive, $13^{\text {th }}$ percentile for fine motor, and $27^{\text {th }}$ percentile for gross motor domains. Max used one to two word utterances to signify possession (e.g., "Mine"), desires (e.g., "I want”), greetings (e.g., "Hi”), and protests (e.g., "No"). He was able to identify pictures of common objects, animals, and characters (e.g., Elmo ${ }^{\mathrm{TM}}$ ), respond to questions (e.g., "Where is it?"), and followed simple directions. In his preschool, Max rarely interacted spontaneously, depending instead on teacher questions (e.g., "Max, what would you like?”) or directives (e.g., "Max "Say, I want....") to verbalise.

\section{Interventionists and setting}

Max's educational programme consisted of 2.5 hours of intensive intervention each day in addition to 4 hours of participation in an integrated preschool class $(6$ children with disabilities and 6 typically developing children) in preparation for placement in his community preschool. Intervention occurred in a partitioned area within the classroom where Max received intensive intervention. Max's teacher (a certified special educator) and teacher's assistant, who were trained in applied behaviour analysis, implemented the intervention procedures.

\section{Identification of communicative targets and materials}

Based on observations of typically developing preschoolers, the authors generated a list of potential controlling stimuli that were not vocal in nature (i.e., did not contain explicit spoken utterances) and corresponding communicative responses. Max's parents selected three appropriate targets: saying "Bless you" when someone sneezed, "Uh oh" when someone dropped something, and "Coming" when someone gestured "come here" by curving their index finger. Items commonly found in the preschool (e.g., crayon or book) were used to teach saying "Uh oh." Different materials (e.g., toy ) were used for the assessment of generalisation.

\section{Response definitions}

A correct response was an unprompted verbal utterance (i.e., saying "Bless you," "Uh oh," or "Coming") emitted within 5 seconds of the presentation of the discriminative stimulus $\left(\mathrm{S}^{\mathrm{D}}\right)$ (i.e., someone sneezing, dropping something, or gesturing "come here").

\section{Design and procedure}

A multiple baseline design across three communicative responses was utilised. Generalisation probes were conducted with novel people in novel settings with novel materials.

\section{Baseline}

During baseline, the interventionist presented the $S^{\mathrm{D}}$, waited 5 seconds, and then terminated the opportunity in the absence of feedback, regardless of a correct, incorrect, or no response. Baseline opportunities (5 opportunities per session per day) were presented between other instructional programmes or while Max was engaged in an activity (e.g., blowing bubbles).

\section{Intervention}

Intervention involved discrete trial instruction in which multiple opportunities were presented in close proximity, with prompts to elicit correct responses, followed by a predetermined reinforcer paired with natural consequences or the use of an error correction procedure ${ }^{[20]}$. One or two intervention sessions, consisting of 10 opportunities per session, were conducted daily. During the first three intervention sessions, the interventionist immediately prompted the correct response. That is, she presented the discriminative stimulus $\left(\mathrm{S}^{\mathrm{D}}\right)$ (e.g., dropped something), immediately prompted the target response with a verbal model (e.g., "Say 'Uh oh"'), and delivered reinforcement (i.e., edible paired with praise and natural consequences, such as saying, "I'll pick it up"). (Note: During the second intervention session address- 
ing the response "Bless you," Max immediately performed the correct response [i.e., said "Bless you"] prior to the delivery of the prompt, therefore correct responses were recorded within the second session.) After the first two intervention sessions for the response "Bless you" and the first three sessions for the responses "Thank you" and "Coming," each subsequent session began with a probe during which the $S^{D}$ was presented followed by a 5 second interval to allow Max to emit the target response. This determined procedures for the remaining opportunities within that session. If Max did not emit the correct response (i.e., emitted a different or no response) during the probe opportunity, corrective feedback (i.e., interventionist said, "No" or "Uh uh") was delivered and the $S^{\mathrm{D}}$ was repeated, followed by a prompt to ensure a correct response. The interventionist then prompted the correct response for the remainder of that session. If Max emitted a correct response on the probe opportunity, reinforcement was delivered and the remaining opportunities for that session involved the delivery of the $S^{D}$ followed by a 5 second interval with reinforcement for correct responses and error correction for incorrect responses (consisting of corrective feedback [e.g., the interventionist said "uh uh"] followed by repetition of the $S^{\mathrm{D}}$ and a prompt to ensure a correct response). Mastery criteria was $80 \%$ independent correct responding during two consecutive sessions across two days and two different interventionists. Following mastery, intervention sessions continued to ensure the skills maintained.

\section{Generalisation}

One generalisation probe opportunity for each response was conducted each week by interventionists (not involved in this intervention) within Max's integrated classroom or in other areas in the school (e.g., gym, hallway) with novel materials (when relevant).

\section{Reliability}

Response and procedural reliability were evaluated by the first author and an undergraduate volunteer research assistant (i.e., reliability coders) who recorded data simultaneously with the interventionist for $51 \%$ of opportunities, distributed across each condition (i.e., baseline, intervention, and generalisation). Percent agreement for response reliability, cumulated across all opportunities, was $94 \%$. For procedural reliability, each intervention opportunity was examined for accurate presentation of each component of intervention; $\mathrm{S}^{\mathrm{D}}$, prompting procedure, and provision of appropriate consequences. Percent agreement for procedural reliability was $96 \%$ for correct presentation of the $\mathrm{S}^{\mathrm{D}}, 90 \%$ for use of

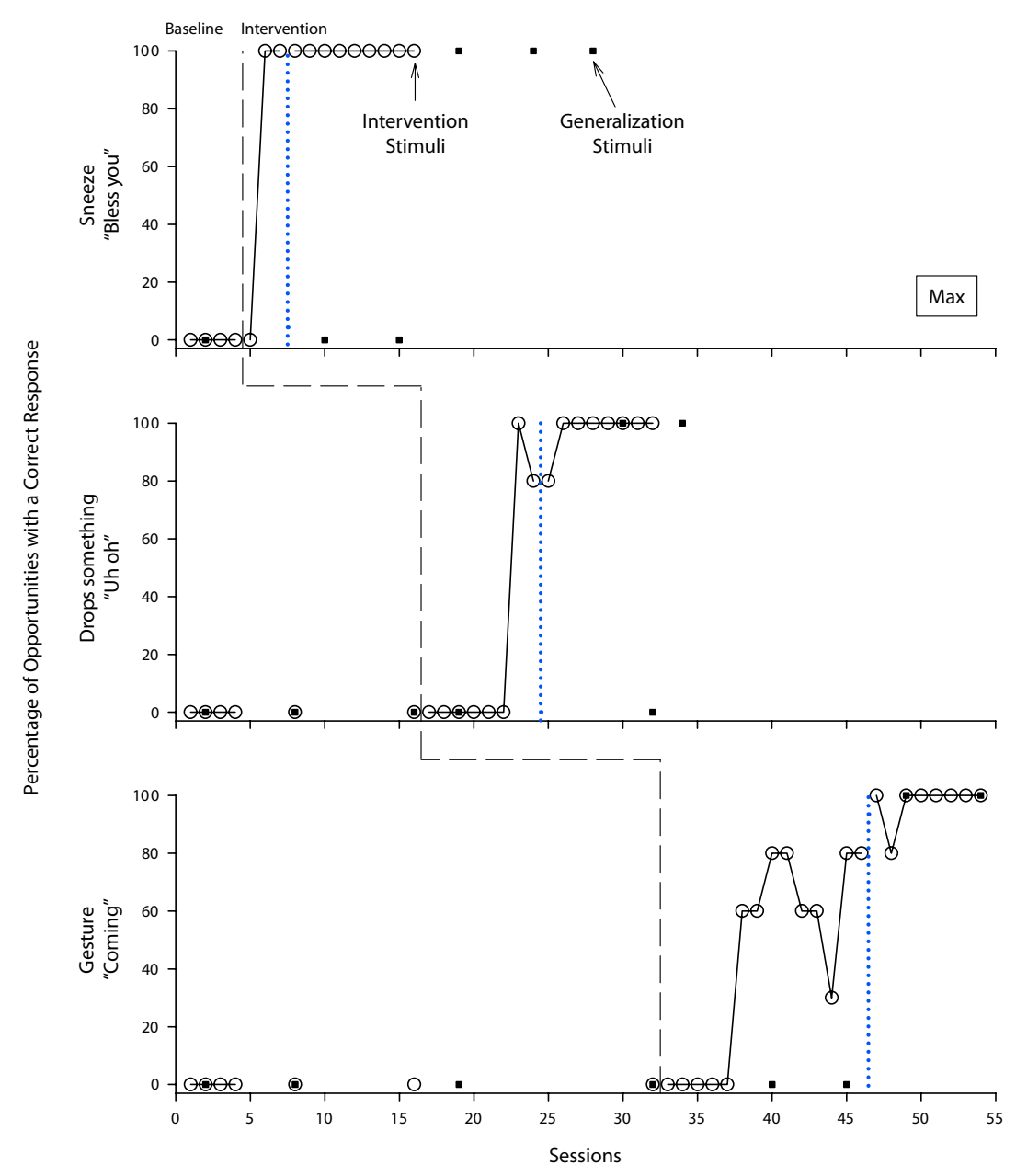

Figure 1 | Percentage of opportunities with a correct response for Max across three communicative responses and performance during generalisation probes Mastery (i.e., performance at or above $80 \%$ across two consecutive sessions, days, and interventionists) is indicated by the blue dotted vertical line.

the correct prompting procedures, and $94 \%$ for delivery of appropriate consequences.

\section{Results and discussion}

FIGURE 1 illustrates Max's performance across the three responses during baseline, intervention, and generalisation probes. During baseline, Max did not emit any target responses (0\%). Max reached mastery criterion (i.e., performed at or above $80 \%$ across two consecutive sessions, days, and interventionists), indicated by a blue dotted vertical line in FIGURE 1, across all three responses (3 sessions for "Bless you," 8 for "Uh oh," and 14 for "Coming"). Max continued to demonstrate all three responses following mastery and generalised across stimuli.

Because of significant impairments in expressive language among children with Down syndrome, identification of effective intervention strategies is imperative. This study supports the use of intensive intervention to address deficits in spontaneous use of language. We hypothesise that, in many instances, children with Down syndrome refrain from spontaneously commu- 
nicating due to not having been taught specific responses. Although it is not possible to predict all stimuli to which a child will be exposed, caregivers can identify those highly likely to occur, as well as those particularly relevant for a child, and implement specific intervention.

The spontaneous utterances taught within this study were acquired relatively quickly which may be due to numerous teaching opportunities within close temporal proximity, characteristic of discrete trial instruction. Others have utilised more naturalistic teaching procedures (e.g. REF 14), demonstrating advantages to both contexts of instruction. Discrete trial instruction allows for multiple teaching opportunities in a relatively short period of time with the use of powerful reinforcers (albeit not necessarily related to the target response). Naturalistic instruction involves the use of naturally reinforcing stimuli and increased likelihood of generalisation. However, in research on spontaneity in children with autism, a greater number of teaching opportunities were required for acquisition within naturalistic contexts ${ }^{[13]}$ than within intensive intervention contexts (e.g. REF 6). In evaluating the relative effectiveness of intensive versus naturalistic interventions, it is worth considering not only the skill to be addressed, but the immediacy with which the child must acquire the skill. Some skills, specifically impaired in children with Down syndrome (e.g., expressive language), may be more conducive to intensive intervention. When a child needs to acquire a skill within a short period of time, a more intensive approach to instruction may be warranted. The comparative effects of intensive and naturalistic intervention for children with Down syndrome remain to be demonstrated.

Problems with generalisation have also been noted when skills are acquired within intensive intervention contexts, however, Max generalised the responses across stimuli. Anecdotally, following Max's acquisition of the "Bless you" response, his father also reported Max using the social nicety at home. We hypothesise that generalisation occurred as a result of Max's ability to recruit natural contingencies of reinforcement across stimuli. As children with Down syndrome encounter potentially socially reinforcing situations, they may not have acquired relevant language forms prohibiting them from recruiting natural social reinforcement. As demonstrated in this study, once acquired, these forms were displayed across environmental stimuli.

Three additional issues warrant future examination. First, in this study responses reflected a range of communicative functions, including a social nicety ("Bless you"), comment ("Uh oh"), and confirmation of a directive ("Coming"). It is important to assess the full range of communicative functions to determine those that are impaired in individual children and then teach each so that children with Down syndrome can interact effectively. Second, because articulation is an area of difficulty for children with Down syndrome ${ }^{[5]}$, increased opportunities to practice communicative targets may enhance performance. In fact, prior to this study, two responses (i.e., "Bless you" and "Coming") were taught to Max through verbal imitation practice. Third, finer discriminations on the part of the child (e.g., when particular responses should and should not be emitted, that is, conditional use of communicative responses) ${ }^{[21,22]}$ should be assessed and directly taught if necessary.

In this study, we explored teaching spontaneous communicative responses to a young child with Down syndrome. Results support the use of an intensive intervention approach to address expressive communication deficits. Further examination of functional communicative targets and the use of intensive intervention approaches to ameliorate communicative impairments prevalent among young children with Down syndrome is warranted. 
1. Miller J. The developmental asynchrony of language development in children with Down syndrome. In Nadel L, editor. The psychobiology of Down syndrome. Cambridge, MA: MIT Press; 1988: p.167-198.

2. Rosin M, Swift E, Bless D, Vetter D. Communication profiles of adolescents with Down syndrome. Journal of Childhood Communication Disorders. 1988;12:49-64.

3. Smith B, Stoel-Gammon C. A longitudinal study of the development of stop consonant production in normal and Down's syndrome children. Journal of Speech and Hearing Disorders. 1983; 48:114-118.

4. Miller J. Lexical development in children with Down syndrome. In Chapman R, editor. Processes in language acquisition and disorders. St. Louis, MO: Mosby; 1992: p.202-216.

5. Kumin L. Intelligibility of speech in children with Down syndrome in natural settings: Parents' perspective. Perceptual and Motor Skills. 1994; 78:301-313.

6. Charlop MH, Schreibman L, Thibodeau MG Increasing spontaneous verbal responding in autistic children using a time delay procedure. Journal of Applied Behaviour Analysis. 1985;18: 155-166.

7. Carr E, Kologinsky E. Acquisition of sign language by autistic children II: Spontaneity and generalization of effects. Journal of Applied Behaviour Analysis. 1983;16:297-314.

8. Halle JW, Baer DM, Spradlin JE. Teachers' generalized use of delay as a stimulus control procedure to increase language use in handicapped children. Journal of Applied Behaviour Analysis. 1981;14:389-409.
9. Charlop MH, Walsh ME. Increasing autistic children's spontaneous verbalizations of affection: an assessment of time delay and peer modeling procedures. Journal of Applied Behaviour Analysis. 1986,19:307-314.

10. Matson JL, Sevin JA, Fridley D, Love SR. Increasing spontaneous language in three autistic children. Journal of Applied Behaviour Analysis. 1990;23:227-233.

11. Matson JL, Sevin JA, Box ML, Francis KL. An evaluation of two methods for increasing self-initiated verbalizations in autistic children Journal of Applied Behaviour Analysis. 1993;26: 389-398.

12. Taylor BA, Levin L. Teaching a student with autism to make verbal initiations: Effects of a tactile prompt. Journal of Applied Behaviour Analysis. 1998;31: 651-654.

13. Charlop MH, Trasowech JE. Increasing autistic children's daily spontaneous speech. Journal of Applied Behaviour Analysis. 1991;24:747-761.

14. Warren SF, Yoder PJ, Gazdag GE, Kim K, Jones HA. Facilitating prelinguistic communication skills in young children with developmental delay. Journal of Speech and Hearing Research. 1993;36:83-97.

15. Hemmeter ML, Ault MJ, Collins BC, Meyer S. The effects of teacher-implemented language instruction within free time activities. Education and Training in Mental Retardation and Developmental Disabilities. 1996;31:203-212.

16. Jones EA, Feeley KM, Takacs J. Teaching children with autism spontaneous responses. Journal of Applied Behaviour Analysis. Forthcoming.

17. Zimmerman IL, Steiner G, Pond RE. Preschool Language Scale. $3^{\text {rd }} \mathrm{Ed}$ (PLS-3). San Antonio, TX:
The Psychological Corporation; 1992.

18. Goldman R, Fristoe M. Goldman Fristoe Test of Articulation. Pines, MN: American Guidance Service Publishers; 1986.

19. Nehring AD, Nehring EFI, Bruni JR, Randolph PL. Learning Accomplishment Profile Diagnostic Standardized Assessment. Lewisville, NC: Kaplan School Supply Corporation; 1992.

20. Lovaas OI. Behavioural treatment and normal educational functioning in young autistic children. Journal of Consulting and Clinical Psychology. 1987,55:3-9.

21. Feeley KM. Examining the use of negative teaching exemplars in establishing a general requesting response in young children with severe disabilities.[doctoral dissertation]. University of Minnesota, Minneapolis; 1999.

22. Reichle J, Sigafoos J. Bringing communicative behaviour under the control of the appropriate stimuli. In Reichle J, York J and Sigafoos J, editors. Implementing augmentative and alternative communication: Strategies for learners with severe disabilities. Baltimore, MD: Paul H. Brooks; 1991 . p.193-213.

\section{Acknowledgements}

We thank Developmental Disabilities Institute for the dedication of resources to this project. We also thank our participant, his parents, and teachers who devoted their time and effort, as well as Jillian Bauza, a Stony Brook student, who assisted with data collection.

Received: 21 September 2006; Accepted 14 February 2007; Published online: 6 August 2007. 